\title{
ATP Is Required at an Early Step in Compensatory Endocytosis in Synaptic Terminals
}

\author{
Ruth Heidelberger \\ Department of Neurobiology and Anatomy, W. M. Keck Center for the Neurobiology of Learning and Memory, University \\ of Texas Houston Health Science Center, Houston, Texas 77030
}

\begin{abstract}
Whole-terminal capacitance measurements were used to examine membrane retrieval that follows $\mathrm{Ca}^{2+}$-triggered exocytosis in single synaptic terminals. Exocytosis was followed by endocytosis only when the internal solution contained a hydrolyzable analog of ATP. ATP- $\gamma$-S, a poorly hydrolyzable ATP analog, did not support endocytosis but instead produced a rapid and profound inhibition of membrane retrieval. Under similar conditions, the GTP analogs GTP- $\gamma$-S and GDP- $\beta$-S failed to block endocytosis, suggesting that ATP is the preferred substrate. Furthermore, the requirement for ATP was indepen-
\end{abstract}

Three distinct patterns of endocytosis have been identified in secretory cells when capacitance measurements are used to monitor membrane retrieval. The first of these, "compensatory endocytosis," is observed immediately after $\mathrm{Ca}^{2+}$-dependent exocytosis and serves to restore the membrane capacitance precisely back to baseline. Compensatory endocytosis typically has a time constant of a few seconds, although after strong stimuli or elevations in basal $\mathrm{Ca}^{2+}$, the recovery time can be quite prolonged (von Gersdorff and Matthews, 1994a,b). This form of endocytosis has been reported in both synaptic terminals (von Gersdorff and Matthews, 1994a,b) and neuroendocrine cells (Smith and Neher, 1997; Engisch and Nowycky, 1998). In neuroendocrine cells and neuronal somata, but not synaptic terminals, $\mathrm{Ca}^{2+}$-triggered endocytosis may also lead to a large undershoot of the baseline capacitance (Thomas et al., 1994; Smith and Neher, 1997; Engisch and Nowycky, 1998; Heidelberger, 1998). This "excess retrieval" is thought to be related to cellular housekeeping functions rather than neurotransmitter release (Smith and Neher, 1997; Engisch and Nowycky, 1998). A third pattern of endocytosis, "rapid endocytosis," has been observed after an exocytotic burst in adrenal chromaffin cells (Artalejo et al., 1995). A similar rapid retrieval of membrane has been observed only at extremely high internal $\mathrm{Ca}^{2+}$ in synaptic terminals (Heidelberger, 1998), and its significance to synaptic function is unclear. Rapid endocytosis in chromaffin cells involves the GTPase dynamin and tyrosine phos-

\footnotetext{
Received April 18, 2001; revised June 6, 2001; accepted June 13, 2001.

This work was supported by National Institutes of Health Grant EY12128, the Esther A. and Joseph Klingenstein Fund, and the Alfred P. Sloan Foundation. I thank Erwin Neher and Gary Matthews for their contributions to the early phases of this project. I thank Andrew Bean and Neal Waxham for stimulating discussions and for performing the HPLC analysis of nucleotide solutions (N. Waxham). I thank Alice Chuang and the Core Grant for Vision Research (National Eye Institute Grant EY10608) for providing statistical support and Kate Pearson for her excellent technical assistance.

Correspondence should be addressed to Ruth Heidelberger, Department of Neurobiology and Anatomy, University of Texas Houston Health Science Center, Houston, TX 77025. E-mail: ruth.heidelberger@uth.tmc.edu.

Copyright (ㄷ) 2001 Society for Neuroscience 0270-6474/01/216467-08\$15.00/0
}

dent of the role of ATP in regulating intraterminal $\mathrm{Ca}^{2+}$, and the role of $\mathrm{Ca}^{2+}$ in endocytosis was different from that of ATP. The results suggest a direct, acute requirement for ATP hydrolysis in compensatory fast endocytosis in synaptic terminals. Given that the capacitance technique detects changes in membrane surface area, ATP must be required for the membrane fission step or at a step that is a prerequisite for membrane fission.

Key words: endocytosis; synaptic vesicle; ATP; synapse; bipolar cell; retina; calcium

phorylation but not clathrin (Artalejo et al., 1995; Nucifora and Fox, 1999). In contrast, very little is specifically known about the underlying molecular mechanism of compensatory endocytosis, particularly at synapses. Because compensatory endocytosis is coupled both temporally and in magnitude to the preceding exocytotic response and is the predominant mechanism in synaptic terminals, it is this form of endocytosis that is likely to play a significant role in synaptic function.

Previous morphological studies have suggested that metabolic energy is required for the replenishment of synaptic vesicles at active zones (Atwood et al., 1972; Schaeffer and Raviola, 1978). ATP has also been shown to be required at multiple reactions in receptor-mediated endocytosis, including at the very early steps of coated pit formation (Smythe et al., 1989; Schmid and Smythe, 1991) and at the membrane fission step that forms a coated vesicle from a coated pit (Smythe et al., 1989; Schmid and Carter, 1990; Schmid and Smythe, 1991). However, because more than one pathway of membrane retrieval exists in nerve terminals (Miller and Heuser, 1984; Koenig and Ikeda, 1996), whether ATP was specifically required at an early step in fast compensatory endocytosis remained uncertain. To address this question, changes in membrane surface area associated with synaptic vesicle fusion and retrieval were monitored using time-resolved capacitance measurements in single synaptic terminals of retinal bipolar neurons, along with measurements of intraterminal $\mathrm{Ca}^{2+}$. The validity of the capacitance approach for these glutamatergic neurons is well established (von Gersdorff et al., 1998). The results demonstrate that, not only is ATP specifically required in the fast compensatory endocytic pathway, but that it is necessary for endocytosis to be initiated.

\section{MATERIALS AND METHODS}

Preparation of synaptic terminals. Synaptic terminals of Mb1 bipolar neurons were prepared acutely from dark-adapted goldfish retina using a combination of enzymatic and mechanical treatment (Heidelberger and Matthews, 1992). Isolated synaptic terminals were identified on the basis of their characteristic appearance, size (terminals of $8-12 \mu \mathrm{m}$ in diam- 
eter), and electrophysiological profile (Kaneko and Tachibana, 1985; Heidelberger and Matthews, 1992). All experiments were performed at room temperature $\left(21-24^{\circ} \mathrm{C}\right)$.

Solutions. External bathing solution for all experiments contained (in $\mathrm{mM}): 115 \mathrm{NaCl}, 2.6 \mathrm{KCl}, 1.6 \mathrm{MgCl}_{2}, 1.0 \mathrm{CaCl}_{2}, 10 \mathrm{HEPES}$, and 11 glucose, $\mathrm{pH} 7.3$ (255-260 mOsm). Standard internal recording solution contained (in $\mathrm{mM}$ ): 85-100 Cs-gluconate, 10 tetraethylammonium (TEA)-Cl, 1-2 $\mathrm{MgCl}_{2}$, 33-65 mM Cs-HEPES, 0.5 GTP, 2 mM MgATP, 0.5 EGTA, and 0.2 fura-2. In some experiments Cs-gluconate was replaced by $\mathrm{Cs}$-glutamate and $\mathrm{TEA}-\mathrm{Cl}$ was reduced to $5 \mathrm{~mm}$. For all internal solutions, free $\mathrm{Mg}^{2+}$ was at least $1 \mathrm{~mm}$. Internal solutions in which free $\mathrm{Ca}^{2+}$ was defined were made by replacing 0.5 EGTA in the standard solution with a combination of $5 \mathrm{~mm}$ EGTA and $2.5 \mathrm{mM} \mathrm{CaCl}_{2}$ to give a free $\mathrm{Ca}^{2+}$ concentration of $\sim 150 \mathrm{nM}$. For ATP- $\gamma-\mathrm{S}$ solutions, ATP- $\gamma$-S was substituted for ATP and $1 \mathrm{~mm}$ additional $\mathrm{MgCl}_{2}$ was added to give $3 \mathrm{~mm} \mathrm{MgCl}_{2}$. GTP- $\gamma-\mathrm{S}$ solutions were based on the standard solution and contained $3.2 \mathrm{~mm}$ GTP- $\gamma-\mathrm{S}$, a total of either 3 or $10 \mathrm{~mm}$ $\mathrm{MgCl}_{2}$, and a reduced ATP concentration of $1 \mathrm{~mm}$. For GDP- $\beta-\mathrm{S}$ solutions, GDP- $\beta$-S replaced GTP in the standard internal solution. The $\mathrm{pH}$ and osmolarity of the final internal solutions were adjusted to 7.25 and $265 \mathrm{mOsm}$, respectively. Note that ATP- $\gamma-\mathrm{S}$ was used rather than omitting ATP because, like other L-type calcium channels, the bipolar neuron calcium channels require ATP to maintain their activity.

The time course of loading of terminals with internal solution was monitored by following the increase in fura- 2 fluorescence. Calculations suggest that loading with nucleotides should be slightly faster than fura-2 (Pusch and Neher, 1988), which is complete within $\sim 50 \mathrm{sec}$ after break-in in synaptic terminals. Therefore, a minimum of $50 \mathrm{sec}$ was allowed for dialysis before the start of an experiment. The nucleotide content of solutions with high ATP and GTP- $\gamma$-S were verified by HPLC using a spheroclone column from Phenomenex (Torrance, CA). $\mathrm{Cs}^{+}$salts were prepared from $\mathrm{CsOH}$ purchased from Aldrich (Steinheim, Germany and Milwaulkee, WI). Fura-2 was obtained from Molecular Probes (Eugene, OR). ATP- $\gamma$-S and GTP were obtained from Boehringer Mannheim (Mannheim, Germany and Indianapolis, IN). GTP- $\gamma$-S was obtained from Calbiochem (La Jolla, CA) and Boehringer Mannheim (Indianapolis, IN). GDP- $\beta$-S was obtained from Calbiochem. All other reagents were from Sigma (Deisenhofen, Germany and St. Louis, MO). Internal solutions were kept on ice and protected from light when not stored in the dark at $-20^{\circ} \mathrm{C}$.

Electrical measurements. Conventional whole-cell recordings were performed on synaptic terminals using Sylgard-coated pipettes with resistances of 7-10 M $\Omega$. Because hydrostatic pressure can influence the time course of endocytosis (R. Heidelberger and G. Matthews, unpublished observations), the hydrostatic pressure in the pipette was adjusted to a constant value with either a feedback-controlled device from Lorenz (Katlenburg-Lindau, Germany) or manually with a micrometercontrolled syringe and monometer. In addition, the angle of the pipette was held constant, and the pipettes were backfilled with a fixed volume of fluid.

Electrical recordings were made using the computer-controlled EPC-9 patch-clamp amplifier from Heka Elektronik (Lambrecht, Germany). Capacitance measurements were performed using the software emulation of a two-phase lock-in amplifier that is provided as part of the EPC-9 Pulse software (Heka Elektronik) or with the automatic capacitance compensation of the EPC-9 amplifier (Chow et al., 1992; Heidelberger et al., 1994). With the software lock-in amplifier, a $1600 \mathrm{~Hz}$ sinusoidal stimulus, $\leq 32 \mathrm{mV}$ peak-to-peak, was applied about the DC holding potential. The resulting current was processed using the Lindau-Neher technique (Lindau and Neher, 1988; Gillis, 1995) to give estimates of the equivalent circuit parameters $\left(C_{\mathrm{m}}, G_{\mathrm{s}}\right.$, and $\left.G_{\mathrm{m}}\right)$. The reversal potential of the measured DC current was assumed to be 0 . For all experiments, the holding potential, $V_{\mathrm{h}}$, was $-60 \mathrm{mV}$ and all depolarizations were to $0 \mathrm{mV}$. Terminals with leak current greater than $-40 \mathrm{pA}$ were excluded from analysis.

Calcium measurements. For measurement of the average intraterminal $\mathrm{Ca}^{2+}$, alternating excitation at 345 and $390 \mathrm{~nm}$ was typically provided by a computer-controlled monochrometer-based system from ASI/T.I.L.L. Photonics (Eugene, OR) as described previously (Messler et al., 1996). In some experiments, alternating excitation was provided by a two-flash lamp system from T.I.L.L. Photonics (Graefeling, Germany). Emitted fluorescence was collected from an $\sim 20$ - $\mu$ m-diameter spot in the object plane through a $470 \mathrm{~nm}$ long-pass and a $540 \mathrm{~nm}$ short-pass filter and, for the monochrometer-based system, detected by a photomultiplier tube (model R928; Hamamatsu, Hamamatsu City, Japan) or photodiode (model S4753-02; Hamamatsu). This fluorescence signal was sampled by the EPC-9 and acquired using the Fura extension of the Pulse software. For the two-flash lamp system, both excitation and emitted light were detected by photodiodes, simultaneously integrated, and digitized (Heinemann et al., 1994). Fura-2 calibrations were performed in terminals using $\mathrm{Ca}^{2+}$-EGTA-buffered solutions (Heidelberger and Matthews, 1992). Because of potential complications of changes in intraterminal $\mathrm{Ca}^{2+}$ altering the rate of endocytosis (von Gersdorff and Matthews, 1994), terminals with resting $\mathrm{Ca}^{2+}>300 \mathrm{nM}$ were excluded from analysis. Analysis. To control for differences in internal solutions and variability in cell preparations, data were either collected in a pairwise manner or compared with control data obtained under identical experimental conditions. Data were exported into Igor from WaveMetrics Inc. (Lake Oswego, OR) for analyses. More than 75 terminals that had $\mathrm{Ca}^{2+}$ and capacitance responses were examined for this study; however, many terminals were excluded from analyses as a result of the strict criteria of a resting $\mathrm{Ca}^{2+}<300 \mathrm{~nm}$ and a leak current less than $-40 \mathrm{pA}$. Terminals were also excluded if the first stimulation was given earlier than $50 \mathrm{sec}$ after break-in. ATP hydrolysis is required for refilling of the releaseready pool of synaptic vesicles (Heidelberger, 1998) (R. Heidelberger, P. Sterling, and G. Matthews, unpublished observations); therefore, in experiments comparing the effects of ATP- $\gamma-\mathrm{S}$ with ATP on endocytosis, only the first endocytotic response was analyzed. For all experiments, $n$ represents the number of terminals examined rather than the total number of times the event was witnessed. All pooled data are expressed as mean \pm SEM. Comparisons between test groups and controls were analyzed with a two-sample $t$ test or a paired $t$ test using SAS software (SAS Institute, Cary, NC). Statistically significant differences are indicated in the text and figure legends.

\section{RESULTS}

\section{ATP is acutely required for fast endocytosis}

Observations from a previous study in which exocytosis was evoked by flash-photolysis of caged $\mathrm{Ca}^{2+}$ provided hints that, in addition to its role in maintaining exocytosis, ATP might be required for fast compensatory endocytosis in synaptic terminals (Heidelberger, 1998). However, this interpretation was tenuous because of the global elevation of $\mathrm{Ca}^{2+}$ and the reported inhibitory effects of high cytosolic $\mathrm{Ca}^{2+}$ on endocytosis (von Gersdorff and Matthews, 1994; Rouze and Schwartz, 1998; Neves and Lagnado, 1999). To address the role of ATP under more controlled conditions, acutely isolated synaptic terminals of retinal bipolar neurons were voltage clamped, and exocytosis followed by compensatory synaptic endocytosis was triggered by stepping the membrane potential from -60 to $0 \mathrm{mV}$. This protocol activates $\mathrm{Ca}^{2+}$ influx through presynaptic L-type $\mathrm{Ca}^{2+}$ channels (Heidelberger and Matthews, 1992) to trigger the release of the neurotransmitter glutamate (Tachibana et al., 1993; von Gersdorff et al., 1998). Changes in surface area associated with membrane addition and retrieval were monitored using time-resolved membrane capacitance measurements, and intraterminal $\mathrm{Ca}^{2+}$ was ratiometrically calculated with the fluorescent $\mathrm{Ca}^{2+}$ indicator dye fura-2 (Heidelberger and Matthews, 1992). As expected (von Gersdorff and Matthews, 1994a), after a $500 \mathrm{msec}$ depolarization, terminals dialyzed with ATP-containing internal solution exhibited exocytosis followed by fast compensatory endocytosis (Fig. $1 A$ ). In contrast, terminals dialyzed with internal solution containing ATP- $\gamma$-S secreted in response to a first stimulus, but they failed to rapidly retrieve membrane (Fig. $1 B$ ). The mean time constant of endocytosis was more than four times longer in terminals with ATP- $\gamma$-S than in ATP terminals (ATP- $\gamma-\mathrm{S}, \tau=$ $26 \pm 8 \mathrm{sec}, n=5$; ATP, $\tau=5.5 \pm 1 \mathrm{sec}, n=6)$, indicating that ATP may be required for fast compensatory endocytosis. This inhibitory action of ATP- $\gamma$-S was observed $<60 \mathrm{sec}$ after achieving the whole-cell recording configuration, suggesting that ATP is acutely required for compensatory endocytosis. However, internal $\mathrm{Ca}^{2+}$ failed to fully return to resting levels after stimulation 




time after break-in (s)

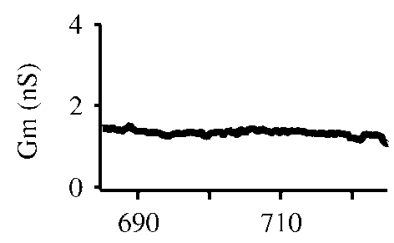

time after break-in (s)



B
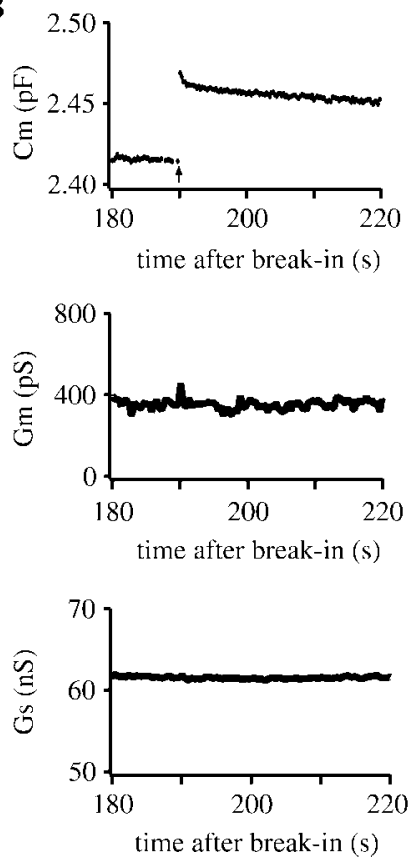

Figure 1. Terminals dialyzed with ATP but not ATP- $\gamma$-S exhibit fast compensatory endocytosis. $A$, The time-resolved capacitance record of an isolated synaptic terminal dialyzed with standard internal solution $(2 \mathrm{~mm}$ ATP). In response to a $500 \mathrm{msec}$ depolarization from a $V_{\mathrm{h}}$ of -60 to 0 $\mathrm{mV}$, the membrane capacitance $\left(C_{\mathrm{m}}\right)$ increased by $\sim 186 \mathrm{fF}$. The time course of restoration of the membrane capacitance back to baseline could be described by a single exponential with a time constant of $\sim 2.96 \mathrm{sec}$. The corresponding membrane conductance $\left(G_{\mathrm{m}}\right)$ and series conductance $\left(G_{\mathrm{s}}\right)$ are shown in the bottom panels. Lack of correlated changes between $C_{\mathrm{m}}$ and $G_{\mathrm{s}}$ or $G_{\mathrm{m}}$ suggest that changes in $C_{\mathrm{m}}$ reflect changes in membrane surface area. $B$, The time-resolved capacitance record of an isolated synaptic terminal dialyzed with internal solution in which $2 \mathrm{mM}$ ATP was replaced by $2 \mathrm{~mm}$ ATP- $\gamma$-S. In response to a $500 \mathrm{msec}$ depolarization from a $V_{\mathrm{h}}$ of -60 to $0 \mathrm{mV}$, the membrane capacitance increased by $\sim 55$ fF. Note the slow time course of membrane retrieval. $G_{\mathrm{m}}$ and $G_{\mathrm{s}}$ are shown in the bottom panels. Again, there are no correlated changes in $C_{\mathrm{m}}$ and $G_{\mathrm{m}}$ or $G_{\mathrm{s}}$. For both $A$ and $B$, timing of the depolarization is given by the arrow. Terminals are from the same trituration.

without ATP. Even when 1 mM EGTA was added to the ATP- $\gamma$-S solution to increase the $\mathrm{Ca}^{2+}$ buffering capacity, the mean resting poststimulus $\mathrm{Ca}^{2+}$ was $\sim 203 \%$ of the prestimulus resting $\mathrm{Ca}^{2+}$ $(n=5)$ compared with ATP controls, in which the poststimulus $\mathrm{Ca}^{2+}$ returned to within $15 \%$ of the basal level $(n=5)$.

The requirement for ATP is not mediated by $\mathbf{C a}^{2+}$

To distinguish between a direct requirement of ATP in fast endocytosis from an indirect requirement mediated by elevation of cytosolic $\mathrm{Ca}^{2+}, \mathrm{Ca}^{2+}$ was defined in the internal solutions to be $150 \mathrm{~nm}$, a value close to resting internal $\mathrm{Ca}^{2+}$ in undialyzed synaptic terminals (Heidelberger and Matthews 1992). Figure 2 shows representative capacitance responses from a pair of terminals dialyzed with $\mathrm{Ca}^{2+}$-EGTA-buffered internal solutions containing either ATP (Fig. $2 A$ ) or ATP- $\gamma-\mathrm{S}$ (Fig. 2B). In both terminals, a $500 \mathrm{msec}$ depolarizing voltage step from -60 to $0 \mathrm{mV}$ evoked a transient increase in intraterminal $\mathrm{Ca}^{2+}$ that triggered the addition of membrane. Whereas the terminal with ATP exhibited a rapid return of membrane capacitance to baseline $(\tau=3.2 \mathrm{sec})$, endocytosis was completely blocked in the terminal with ATP- $\gamma$-S. The mean time constant of endocytosis in terminals dialyzed with $\mathrm{Ca}^{2+}$-buffered internal solution containing

A


Figure 2. ATP- $\gamma$-S does not support rapid endocytosis, even when differences in internal $\mathrm{Ca}^{2+}$ are minimized. $A, B$, Top panels, The capacitance records from isolated synaptic terminals dialyzed with $\mathrm{Ca}^{2+}$ EGTA-buffered internal solutions containing either ATP $(A)$ or ATP- $\gamma$-S $(B)$. Exocytosis was evoked by a $500 \mathrm{msec}$ depolarization from -60 to 0 $\mathrm{mV}$. Fast endocytosis followed exocytosis with ATP but not ATP- $\gamma-\mathrm{S}$. Timing of the depolarizations are indicated by the arrows. Bottom panels, The corresponding $\mathrm{Ca}^{2+}$ records, ratiometrically calculated from changes in fura-2 fluorescence.

ATP was $2.58 \pm 0.32 \mathrm{sec}(n=8)$ (Fig. $3 A)$, in good agreement with values reported previously for the time course of fast endocytosis in synaptic terminals (von Gersdorff and Matthews, 1994a,b). In contrast, the mean time constant of endocytosis was $67.0 \pm 30 \mathrm{sec}(n=6)$ in ATP- $\gamma-\mathrm{S}$ terminals (Fig. $3 A)$, excluding four terminals in which there was no return of the membrane capacitance during the observed time interval ( $>40 \mathrm{sec}$ after stimulation). The inhibition of fast endocytosis by ATP- $\gamma$-S, introduced into the terminals as a $\mathrm{Li}^{+}$salt, could not be attributed to the presence of $\mathrm{Li}^{+}$. At concentrations of up to $20 \mathrm{~mm}$, $\mathrm{Li}^{+}$did not significantly effect the time course of fast endocytosis $(\tau=2.69 \pm 0.85 \mathrm{sec}, n=5)$. In addition, the $\mathrm{Li}^{+}$salt of another nucleotide, GTP- $\gamma$-S, did not block fast endocytosis (Fig. 4).

The $\mathrm{Ca}^{2+}$ records in Figure 2 indicate that intraterminal $\mathrm{Ca}^{2+}$ returned to baseline after closure of $\mathrm{Ca}^{2+}$ channels with either ATP or ATP- $\gamma-\mathrm{S}$ when using a $\mathrm{Ca}^{2+}$-buffered internal solution. Analysis of the $\mathrm{Ca}^{2+}$ records indicated that there were no significant differences in the resting $\mathrm{Ca}^{2+}$ before and after a stimulus between terminals with ATP or ATP- $\gamma$-S (Fig. $3 B$ ). Furthermore, there was no statistically significant difference in the peak $\mathrm{Ca}^{2+}$ after membrane depolarization or in the time course or recovery of $\mathrm{Ca}^{2+}$ to basal levels (Fig. $3 B$ ). Thus, intraterminal $\mathrm{Ca}^{2+}$ was well controlled in these experiments and comparable between groups. In addition, little rundown of $I_{\mathrm{Ca}}$ was observed with successive depolarizations in terminals with either ATP or ATP$\gamma$-S, consistent with the suggestion that $\mathrm{Ca}^{2+}$ did not remain high under the membrane (data not shown). Therefore, the inability of terminals with ATP- $\gamma$-S to rapidly retrieve membrane after exocytosis cannot be ascribed to differences in $\mathrm{Ca}^{2+}$ between terminals with ATP or ATP- $\gamma-\mathrm{S}$, indicating that the role of ATP in fast endocytosis is independent of its role in regulating intraterminal $\mathrm{Ca}^{2+}$.

\section{Neither GTP- $\boldsymbol{\gamma}$-S nor GDP- $\boldsymbol{\beta}$-S inhibit fast endocytosis}

To determine whether the observed requirement for ATP was direct or mediated via the intraterminal conversion of ATP- $\gamma-\mathrm{S}$ to 
A

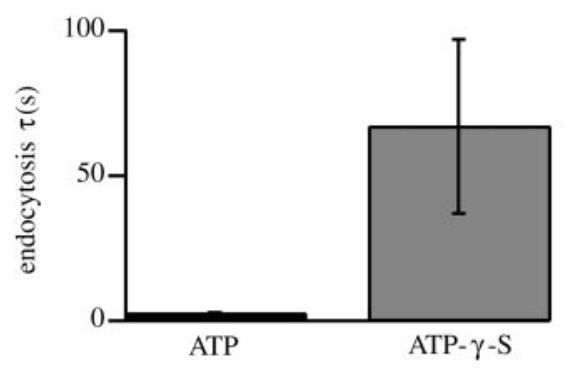

B
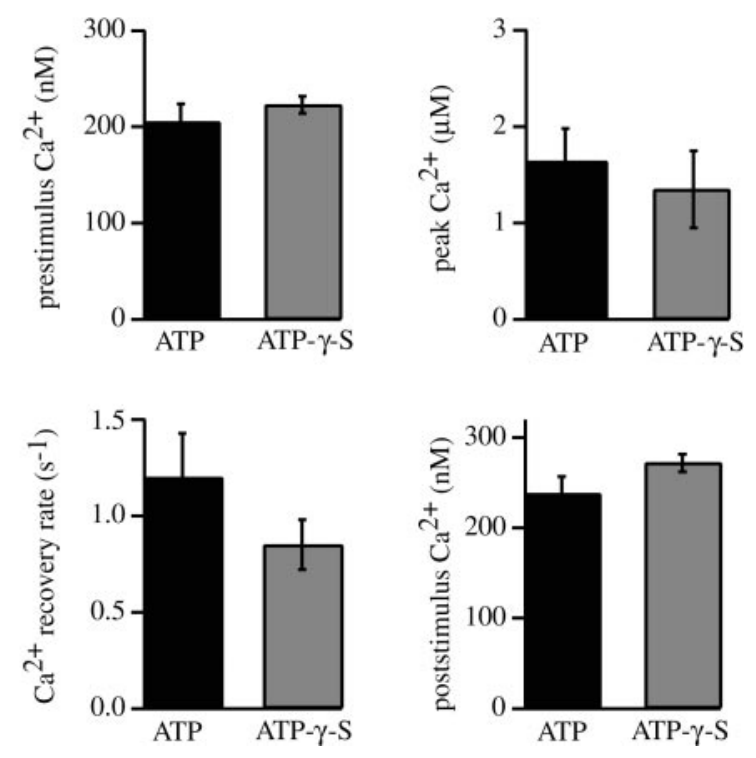

Figure 3. The ATP requirement for endocytosis is independent of intraterminal $\mathrm{Ca}^{2+} . A$, Exocytosis followed by endocytosis was evoked by a $500 \mathrm{msec}$ depolarization from -60 to $0 \mathrm{mV}$. The mean endocytosis time constant is shown for terminals dialyzed with $\mathrm{Ca}^{2+}$-EGTA-buffered internal solutions containing either ATP $(n=8$; black bar) or ATP- $\gamma$-S $(n=6$; gray bar $)$. Four terminals dialyzed with ATP- $\gamma$-S-containing internal solution failed to endocytose in the $>40 \mathrm{sec}$ after exocytosis and are not included in this figure. $B$, There are no statistical differences in the mean $\mathrm{Ca}^{2+}$ parameters between terminals with ATP versus ATP- $\gamma-\mathrm{S}$ when $\mathrm{Ca}^{2+}$-buffered internal solutions are used. Same group of terminals as in $A$. Data are expressed as mean \pm SEM.

GTP- $\gamma$-S, terminals were dialyzed with internal solution in which (1) GTP was omitted and the nonhydrolyzable GTP analog GTP- $\gamma$-S was added at a concentration of $3.2 \mathrm{mM}$, (2) the ATP concentration was reduced from 2 to $1 \mathrm{~mm}$, and (3) free $\mathrm{Mg}^{2+}$ concentration was either 2 or $10 \mathrm{~mm}$ to facilitate nucleotide exchange. Figure $4 A$ shows a representative recording. Each exocytotic response was followed by the rapid retrieval of membrane and the restoration of membrane capacitance to baseline. That terminals can exocytose in the presence of GTP- $\gamma-\mathrm{S}$ is not surprising given that the inhibition of exocytosis by GTP- $\gamma-\mathrm{S}$ is a very slow process (Hess et al., 1993; Artalejo et al., 1995). Interestingly, the mean time constant of endocytosis in GTP- $\gamma$-S terminals ( $\tau=3.19 \pm 0.72 \mathrm{sec}, n=3$ terminals, 7 responses) was virtually identical to controls $(\tau=3.20 \pm 0.56 \mathrm{sec}, n=8)$ for depolarizations $<1 \mathrm{sec}$ in duration (Fig. $4 B$ ) and quite distinct from the prolonged time course of endocytosis observed with ATP- $\gamma$-S (Figs. 1-3). Longer depolarizations, which give rise to slower rates of endocytosis (von Gersdorff and Matthews,
$\mathbf{A}$

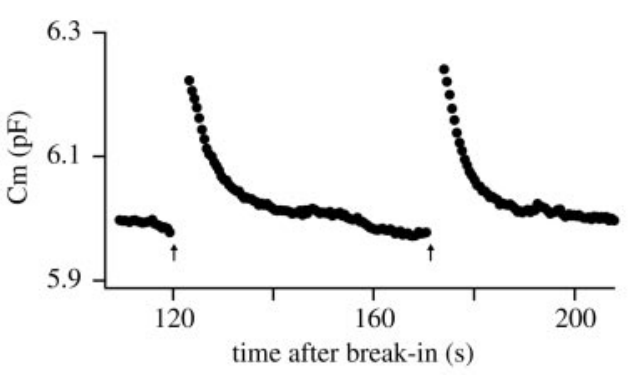

B

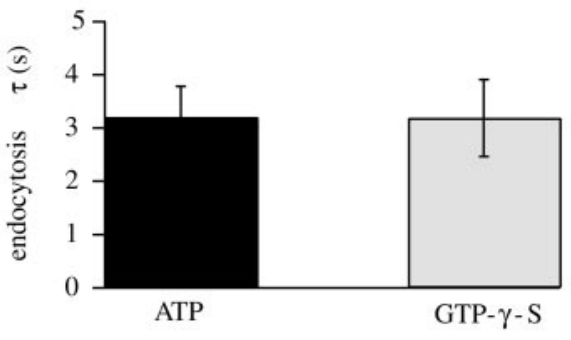

C

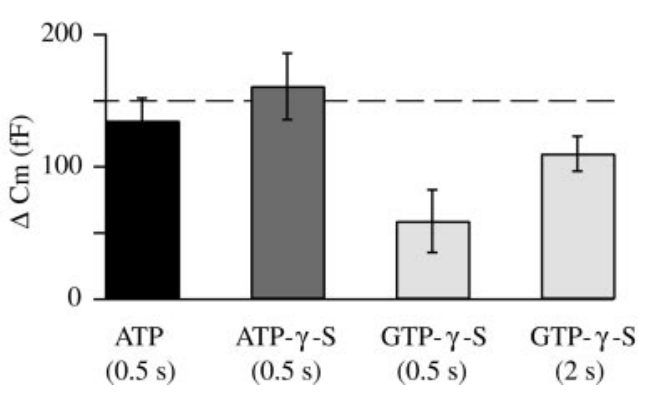

Figure 4. GTP- $\gamma$-S does not block endocytosis, but it does decrease the amplitude of exocytosis. $A$, Capacitance record from the synaptic terminal of a bipolar neuron that was dialyzed with internal solution containing $3.2 \mathrm{~mm}$ GTP- $\gamma$-S and $2 \mathrm{~mm} \mathrm{Mg}{ }^{2+}$. Two $2 \mathrm{sec}$ depolarizations from -60 to $0 \mathrm{mV}$ were given at the times indicated by the arrows to evoke exocytosis. Note the reproducibility of the response. The time constant of endocytosis was $\sim 4$ sec. $B$, Pooled data showing the average time constant of endocytosis from five cells (9 responses) dialyzed with GTP- $\gamma$-S compared with ATP terminals ( 2 or $10 \mathrm{~mm} ; n=8)$. In GTP- $\gamma$-S cells, free $\mathrm{Mg}^{2+}$ was either $2 \mathrm{~mm}(n=3)$ or $10 \mathrm{~mm}(n=2)$. Voltage steps were from -60 to $0 \mathrm{mV}$ and were $0.25-1 \mathrm{sec}$ in duration. Data expressed as mean \pm SEM. $C$, The amplitude of the capacitance response to a $500 \mathrm{msec}$ depolarization was diminished in terminals with GTP- $\gamma-\mathrm{S}(n=5$; light gray bar) relative to terminals with Ca-EGTA-buffered internal solutions containing either ATP $(n=13$; black bar $)$ or ATP- $\gamma$-S $(n=15$; dark gray bar) or literature estimates (dotted line) of the average size of the releaseready pool of synaptic vesicles in bipolar neuron synaptic terminals (Heidelberger, 2001). Increasing the duration of $\mathrm{Ca}^{2+}$ influx to $2 \mathrm{sec}$ increased the amplitude of the capacitance response in GTP- $\gamma$-S terminals ( $n=6$ terminals, 12 responses).

1994a,b), failed to consistently reveal an inhibitory effect of GTP$\gamma$-S on endocytosis. Of the six terminals with GTP- $\gamma$-S that met the criteria for analysis, only one did not exhibit compensatory endocytosis, and there was no statistically significant difference between the mean time constant for endocytosis after a $2 \mathrm{sec}$ depolarization in terminals with GTP- $\gamma-\mathrm{S}$ compared with controls $(\mathrm{GTP}-\gamma-\mathrm{S}, \tau=13.66 \pm 4.65 \mathrm{sec}, n=6$ terminals, 12 responses; controls, $\tau=5.46 \pm 1.93 \mathrm{sec}, n=5$ terminals, 8 responses; $p=0.13)$. GTP- $\gamma-\mathrm{S}$ did appear to have a suppressive effect on the mean amplitude of the membrane addition triggered by a $500 \mathrm{msec}$ depolarization (Fig. $4 C$ ). This could be overcome by increasing the duration of the membrane depolarization (Fig. $4 C$ ), consistent with a smaller average peak $I_{\mathrm{Ca}}$ in GTP- $\gamma-\mathrm{S}$ terminals (GTP- $\gamma$-S, $-66 \pm 5 \mathrm{pA}, n=7$; GTP, $-173 \pm 18 \mathrm{pA}$, 
A

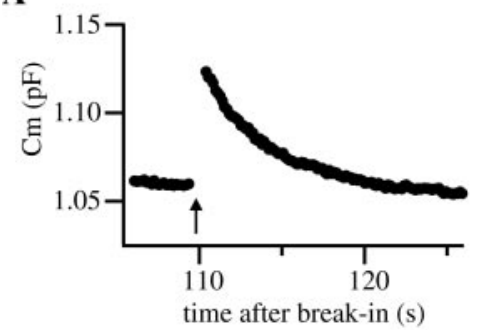

B



Figure 5. GDP- $\beta$-S does not inhibit endocytosis. $A$, Capacitance record from an isolated synaptic terminal that was dialyzed with an internal solution containing GDP- $\beta$-S in place of GTP. Exocytosis was evoked by a $500 \mathrm{msec}$ depolarization from -60 to $0 \mathrm{mV}$. Timing of depolarization is indicated by the arrow. The time constant of membrane recovery was 3.5 sec. $B$, Pooled data show that GDP- $\beta$-S terminals $(n=4$; gray bar $)$ endocytosed with a nearly identical time course as ATP terminals ( 2 or 10 $\mathrm{mM} ; n=8$; black bar) after $500 \mathrm{msec}$ depolarizations (GDP- $\beta$-S) or $0.250-1$ sec depolarizations (ATP).

$n=12)$. GTP- $\gamma$-S has been reported to decrease $I_{\mathrm{Ca}}$ in adrenal chromaffin cells (Artalejo et al., 1995) and in neurons (Scott et al., 1991). G-proteins may also inhibit exocytosis downstream of $\mathrm{Ca}^{2+}$ entry (Blackmer et al., 2001).

Next, the nonhydrolyzable guanosine diphosphate GDP- $\beta$-S was substituted for GTP in the internal solution. GDP- $\beta$-S also failed to block fast endocytosis (Fig. $5 A$ ). The mean time constant of endocytosis in terminals dialyzed with GDP- $\beta$-S was $3.06 \pm$ $0.86 \mathrm{sec}(n=4)$ (Fig. $5 B)$. Longer depolarizations $(2-5 \mathrm{sec}$ in duration) also failed to block fast endocytosis $(\tau=4.96 \pm 0.45$ sec, $n=5$ ). As with GTP- $\gamma$-S, the average amplitude of the capacitance response with GDP- $\beta$-S after a $500 \mathrm{msec}$ depolarization was smaller ( $58 \pm 18 \mathrm{fF}, n=4)$ than the average size of the response with ATP (Fig. $4 C$ ), and $I_{\mathrm{Ca}}$ was smaller, on average, in amplitude $(-49 \pm 7 \mathrm{pA}, n=4)$. The lack of a dramatic, quick inhibition of endocytosis by either GTP- $\gamma$-S or GDP- $\beta$-S suggests that the rapid inhibition of fast endocytosis by ATP- $\gamma$-S reflects an acute and specific requirement for ATP over GTP.

\section{Depletion of ATP does not mediate the reported calcium-dependent inhibition of fast endocytosis}

Endocytosis is $\mathrm{Ca}^{2+}$ sensitive in nerve terminals, with higher internal $\mathrm{Ca}^{2+}$ concentrations slowing the rate of membrane retrieval (von Gersdorff and Matthews, 1994; Hsu and Jackson, 1996; Neves and Lagnado, 1999). However, reports from other cells have indicated that elevated internal $\mathrm{Ca}^{2+}$ may stimulate endocytosis (Engisch and Nowycky, 1998; Klingauf et al., 1998; Sankaranarayanan and Ryan, 2001). Because intraterminal $\mathrm{Ca}^{2+}$ is regulated primarily by plasma membrane $\mathrm{Ca}^{2+}$ ATPases (Zenisek and Matthews, 2000), it is conceivable that depletion of ATP attributable to high $\mathrm{Ca}^{2+}$ might underlie the reported $\mathrm{Ca}^{2+}$-dependent inhibition of endocytosis in synaptic terminals. To test this hypothesis, the relationship between ATP, $\mathrm{Ca}^{2+}$, and the rate of compensatory membrane retrieval was examined. First, ATP in the internal solution was increased from 2 to $10 \mathrm{~mm}$ (Fig. 6). After membrane depolarization, terminals with high ATP exhibited fast endocytosis after $\mathrm{Ca}^{2+}$-triggered exocytosis with time constants indistinguishable from controls $(2 \mathrm{~mm}$ ATP, $\tau=2.85 \pm 0.70 \mathrm{sec}, n=18 ; 10 \mathrm{~mm} \mathrm{ATP}, \tau=3.2 \pm 0.58 \mathrm{sec}, n=$ 4 terminals, 8 responses), indicating that $2 \mathrm{~mm}$ ATP is sufficient to support fast endocytosis in response to moderate stimulation. When the duration of depolarization was increased to $2 \mathrm{sec}$, the time constant of endocytosis increased as expected (von Gers-
A

B
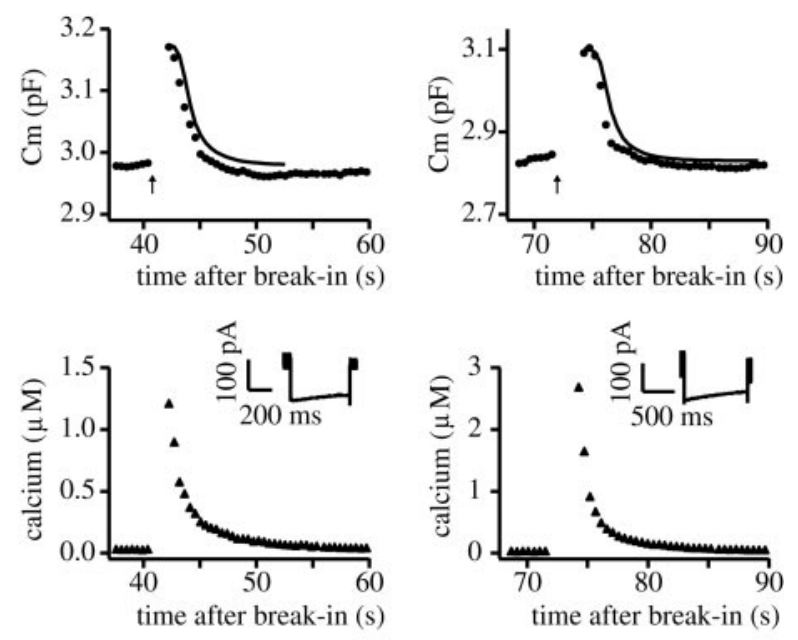

C

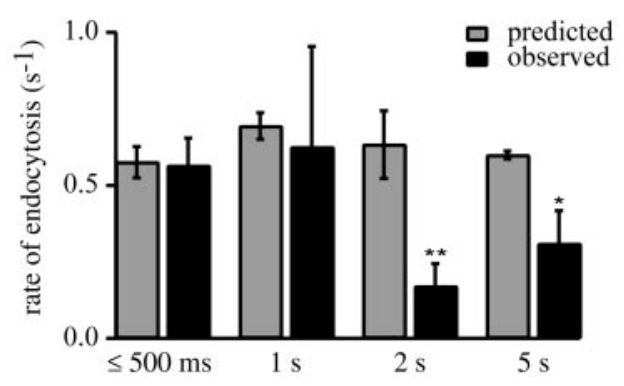

Figure 6. The time course of $\mathrm{Ca}^{2+}$ recovery predicts the time course of endocytosis. $A, B$, Top panels show the capacitance records from synaptic terminals of bipolar neurons dialyzed with internal solution containing 10 mM ATP and stimulated to exocytose with either a $500 \mathrm{msec}(A)$ or $1 \mathrm{sec}$ $(B)$ depolarization from -60 to $0 \mathrm{mV}$. Bottom panels, The ratiometrically calculated intraterminal $\mathrm{Ca}^{2+}$ determined with fura-2. Insets show the corresponding $\mathrm{Ca}^{2+}$ current. The thickness of the trace that precedes and follows the inward current carried by $\mathrm{Ca}^{2+}$ is attributable to the superimposed sine wave stimulus used to monitor membrane capacitance. Curves in the top panels are the time course of membrane recovery predicted from the recovery time course of intraterminal $\mathrm{Ca}^{2+}$. Curves were drawn according to the following: $C_{\mathrm{m}}(t)=a+b e^{-\alpha \mathrm{t}}$, where $\alpha(t)=$ $0.54\left(1-1 /\left(1+\left(0.460 /\left[\mathrm{Ca}^{2+}\right]\right)^{4}\right)\right)$, from von Gersdorff and Matthews (1994b). C, Black bars show the mean rate of endocytosis experimentally observed in terminals with $10 \mathrm{~mm}$ ATP after depolarizations of the indicated durations from -60 to $0 \mathrm{mV}$. Gray bars show the rate of endocytosis predicted from the recovery time course of intraterminal $\mathrm{Ca}^{2+}$. For mild to moderate duration depolarizations, the time course of endocytosis matched the time course of endocytosis predicted by the time course of recovery of intraterminal $\mathrm{Ca}^{2+}$ in terminals with 10 ATP. However, after a $2 \mathrm{sec}$ depolarization, there was a statistically significant difference between the measured and the predicted rates of endocytosis $(p<0.005)$. After a $5 \mathrm{sec}$ depolarization, the measured and predicted rates were also significantly different $(p<0.07)$. For $\leq 500 \mathrm{msec}, n=4$ responses, 2 terminals. For $1 \mathrm{sec}, n=2$ responses, 1 terminal. For $2 \mathrm{sec}$, $n=4$ responses, 3 terminals. For $5 \mathrm{sec}, n=5$ responses, 3 terminals. Data are expressed as mean $\pm \mathrm{SEM}$.

dorff and Matthews, 1994a,b), but the mean time constants of endocytosis were not statistically different between the two conditions ( $10 \mathrm{~mm}$ ATP, $4.82 \pm 0.87 \mathrm{sec}, n=3$ terminals, 6 responses; $2 \mathrm{~mm}$ ATP, $5.46 \pm 1.93 \mathrm{sec}, n=4$ terminals, 8 responses). These results suggest that depletion of cytosolic ATP does not underlie the prolongation of the time course of compensatory endocytosis observed with a long depolarization.

The question of whether the reported relationship between $\mathrm{Ca}^{2+}$ and the time course of endocytosis (von Gersdorff and 
Matthews, 1994b) still held when ATP was high was addressed next. If this relationship did not hold, this would also lend support to the hypothesis that inhibition of endocytosis by elevated intraterminal $\mathrm{Ca}^{2+}$ was not directly mediated by $\mathrm{Ca}^{2+}$ but rather by ATP depletion. After the closure of voltage-gated $\mathrm{Ca}^{2+}$ channels, intraterminal $\mathrm{Ca}^{2+}$ typically recovered with a time course described by a single exponential function (Fig. 6). The predicted time course of endocytosis was calculated from this using the published relationship between intraterminal $\mathrm{Ca}^{2+}$ and the rate of membrane retrieval (von Gersdorff and Matthews, 1994b). The time course of endocytosis predicted by the intraterminal $\mathrm{Ca}^{2+}$ (Fig. 6A, curve) is superimposed on the record of membrane capacitance (Fig. $6 A$, dots). There is good agreement between the time course of endocytosis that was predicted by recovery of internal $\mathrm{Ca}^{2+}$ and the observed time course of endocytosis. Figure $6 B$ shows a similar analysis of a $1 \mathrm{sec}$ depolarization. As has been noted previously for long depolarizations (von Gersdorff and Matthews, 1994; Neves and Lagnado, 1999), the capacitance record exhibited a brief delay between the end of membrane addition and the start of endocytosis, and this delay was mimicked by the time course of endocytosis predicted from the time course of $\mathrm{Ca}^{2+}$ recovery (Fig. $5 B$ ).

To better compare the predicted time course of endocytosis with the observed time course, both time courses after the delays were fitted with single exponential functions, and the resultant rate constants were compared (Fig. 6C). For the terminals stimulated with a 250-500 msec depolarization, the predicted rate constant of endocytosis and the observed rate constant for endocytosis were indistinguishable (predicted rate constant, $0.576 \pm$ $0.044 \mathrm{sec}^{-1}$; observed rate constant, $\left.0.562 \pm 0.080 \mathrm{sec}^{-1} ; n=4\right)$. Similarly, the predicted rate constant of endocytosis and the observed rate constant of endocytosis evoked by $1 \mathrm{sec}$ depolarizations were in good agreement (predicted, $0.694 \pm 0.02 \mathrm{sec}^{-1}$; observed, $0.625 \pm 0.165 \mathrm{sec}^{-1} ; n=2$ ). These findings suggest that, for mild to moderate stimulation protocols, the rate of fast endocytosis does follow a fourth-order dependence on the average cytosolic $\mathrm{Ca}^{2+}$ (von Gersdorff and Matthews, 1994), provided that the requirement for ATP is met. For depolarizations $2-5 \mathrm{sec}$ in duration, the observed time course of endocytosis was significantly slower than that predicted by the rate of recovery of intraterminal calcium (observed rate constant, $0.254 \pm 0.068$ $\mathrm{sec}^{-1}$; predicted rate constant, $\left.0.613 \pm 0.039 \mathrm{sec}^{-1} ; n=10\right)$, consistent with previous reports (von Gersdorff and Matthews, 1994). Although the difference between the observed rate of endocytosis and the rate predicted by the cytosolic calcium achieved statistical significance only for depolarizations $\geq 2 \mathrm{sec}$ in duration, there was a trend for the disparity between the observed rate and the predicted rate of endocytosis to increase with increasing stimulus duration. This is consistent with an activitydependent suppression in the apparent rate of fast endocytosis. The mechanism(s) underlying this apparent slowing is unknown, but the present experiments with high intraterminal ATP suggest that local depletion of ATP is not likely to be the major mechanism.

\section{DISCUSSION}

Although there have been indications that ATP may be required for membrane retrieval, the present study is the first to specifically examine the role of ATP in fast compensatory endocytosis in a synaptic terminal. The data indicate that ATP, apart from its role in regulating intraterminal $\mathrm{Ca}^{2+}$, is required for fast compensatory endocytosis that follows glutamate exocytosis in retinal bi- polar neurons. Interestingly, the inhibition of endocytosis by ATP- $\gamma$-S was evident after the very first round of exocytosis and as early as $1 \mathrm{~min}$ after achieving the whole-cell recording configuration. This suggests that fast compensatory endocytosis has an acute and dynamic requirement for ATP.

The inability of GTP- $\gamma$-S and GDP- $\beta$-S to affect fast compensatory endocytosis in synaptic terminals indicates that hydrolysis of ATP, rather than GTP, may be acutely required. This is an important observation because it implies that the mechanism of fast compensatory endocytosis is different from that of the rapid endocytosis observed in calf adrenal chromaffin cells after an exocytotic burst, which is inhibited by both GTP- $\gamma$-S and GDP$\beta$-S (Artalejo et al., 1995; Nucifora and Fox, 1999). Furthermore, these results suggest that dynamin, a GTPase with a well documented role in membrane fission in receptor-mediated endocytosis (Cremona and De Camilli, 1997; Schmid et al., 1998), may play little role in compensatory synaptic endocytosis, although this remains to be directly tested. It is also conceivable that a large $\mathrm{Ca}^{2+}$ signal, such as that produced by a combination of flash-photolysis of caged calcium and membrane depolarization (Heidelberger, 1998), may reveal a form of rapid endocytosis that is sensitive to GTP in synaptic terminals. However, the present study focused on the regulation of compensatory endocytosis that follows exocytosis triggered by $\mathrm{Ca}^{2+}$ influx through voltage-gated channels because of the physiological relevance of this type of stimulation. As such, the data provide a clear indication that ATP, but not GTP, is acutely required for the fast compensatory endocytosis that follows exocytosis triggered by $\mathrm{Ca}^{2+}$ influx in synaptic terminals.

Provided that at a minimum of $1 \mathrm{~mm}$ ATP was supplied internally, the rate of synaptic endocytosis was independent of ATP concentration and followed the previously described fourth-order relationship between the rate of synaptic endocytosis and intraterminal $\mathrm{Ca}^{2+}$ quite well (von Gersdorff and Matthews, 1994). This is an important conformation because, in addition to reports that high intraterminal $\mathrm{Ca}^{2+}$ can suppress endocytosis in nerve terminals (von Gersdorff and Matthews, 1994; Hsu and Jackson, 1996; Rouze and Schwartz, 1998; Neves and Lagnado, 1999; Cousin and Robinson, 2000), intracellular $\mathrm{Ca}^{2+}$ has also been suggested to favor fast endocytosis (Engisch and Nowycky, 1998; Klingauf et al., 1998; Sankaranarayanan and Ryan, 2001) or have little effect on membrane retrieval (Ramaswami et al., 1994; Wu and Betz, 1996). Interestingly, the discord between the rate of endocytosis predicted by the $\mathrm{Ca}^{2+}$ time course and the experimentally observed rate after strong stimulation was not ameliorated by high ATP. This suggests that local depletion of ATP, in addition to not mediating the $\mathrm{Ca}^{2+}$ dependence of endocytosis under standard conditions, does not underlie the profound slowing of the time course of endocytosis that is observed after strong stimulation protocols (von Gersdorff and Matthews, 1994a,b; Neves and Lagnado, 1999; present study). Together, these observations establish that ATP plays a different role in regulating compensatory endocytosis in synaptic terminals than $\mathrm{Ca}^{2+}$.

So where might the ATP-dependent step in compensatory synaptic endocytosis lie? The capacitance approach, because it monitors membrane addition and retrieval, indicates that ATP is required for membrane fission. Therefore, the observed acute requirement for ATP in compensatory synaptic endocytosis must reflect either a requirement at the membrane fission step (Fig. $7 A$ ) or a step that is absolutely a prerequisite for and temporally associated with membrane fission (Fig. $7 B$ ). Precedence for the first role comes from receptor-mediated endocytosis, in which 

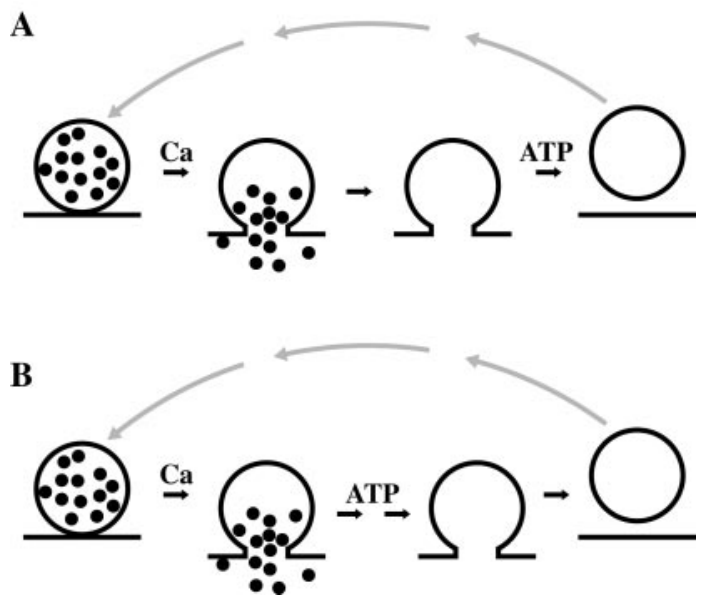

Figure 7. Possible locations of an early requirement for ATP in the fast compensatory endocytosis pathway in synaptic terminals. $A$, ATP may be required for the membrane fission step of the fast compensatory pathway, perhaps by acting as an energy source. $B$, ATP may be required for a postfusion step that is prerequisite for membrane retrieval via the fast compensatory pathway but not be needed for fission. This ATPdependent step might reflect the disassembly and sorting of SNARE complexes. In addition, the possibility that ATP may both play a prefission role and act at the fission step is not excluded.

ATP has been suggested to be necessary for the creation of a coated vesicle from a coated pit (Smythe et al., 1989; Schmid and Carter, 1990; Schmid and Smythe, 1991). This interaction could be mediated by actin, an ATPase that may act as a force generator during fission (Lamaze et al., 1997; Qualmann et al., 2000). A prefission role for ATP may be subserved by ATPases such as $N$-ethylmaleimide-sensitive factor (NSF) or Hrs-2, both of which are implicated in early steps of membrane retrieval by virtue of their roles in dissembling and/or sorting soluble NSF attachment protein receptor (SNARE) proteins (Hay and Scheller, 1997; Kawasaki et al., 1998; Bean et al., 2000). In particular, ATP- $\gamma$-Sbound NSF is known to inhibit disassembly of the 20S SNARE complex, whereas without ATP, this stable complex is not formed (Hanson et al., 1997). Thus, by locking the 20S complex, ATP- $\gamma$-S may uniquely inhibit protein sorting with the consequence that newly added membrane is unable to be retrieved by the fast compensatory pathway. Alternative explanations are also possible. ATP could regulate an early step in compensatory endocytosis via a phosphorylation reaction that is poorly supported by ATP- $\gamma$-S. In addition, ATP- $\gamma$-S could conceivably inhibit endocytosis by thiophosphorylating a protein important for triggering endocytosis when in its dephosphorylated state. This would be consistent with the observation that the rate of endocytosis is enhanced when protein phosphorylation is inhibited (Henkel and Almers, 1996; Kavalali et al., 1999). Unfortunately, the ATP requirement of the calcium channels in synaptic terminals does not allow this hypothesis to be readily examined. However, in experiments in which intraterminal $\mathrm{Ca}^{2+}$ was elevated via flashphotolysis of caged $\mathrm{Ca}^{2+}$, compensatory endocytosis was lost when ATP was not included in the internal solution (Heidelberger et al., 1994; Heidelberger, 1998), favoring the hypothesis that ATP hydrolysis, rather than dephosphorylation of a protein, may be required for endocytosis. However, as stated previously, the global elevation of cytosolic $\mathrm{Ca}^{2+}$ in photolysis experiments makes a mechanistic interpretation of these data difficult. Clearly, it will be of great interest to determine the underlying mechanism of ATP action in the fast compensatory endocytosis pathway. The present results lead the way by suggesting that, in a glutamatergic synaptic terminal, ATP is involved in a step or steps necessary for membrane fission after the $\mathrm{Ca}^{2+}$-dependent vesicular release of neurotransmitter.

\section{REFERENCES}

Artalejo CR, Henley JR, McNiven MA, Palfrey HC (1995) Rapid endocytosis coupled to exocytosis in adrenal chromaffin cells involves $\mathrm{Ca}^{2+}$ GTP, and dynamin but not clathrin. Proc Natl Acad Sci USA 92:8328-8332.

Atwood HL, Lang F, Morin WA (1972) Synaptic vesicles: selective depletion in crayfish excitatory and inhibitory axons. Science 176:1353-1355.

Bean AJ, Davanger S, Chou MF, Gerhardt B, Tsujimoto S, Chang Y (2000) Hrs-2 regulates receptor-mediated endocytosis via interactions with Eps15. J Biol Chem 275:15271-15278.

Blackmer T, Larson EC, Takahashi M, Martin TF, Alford S, Hamm HE (2001) G protein $\beta \gamma$ subunit-mediated presynaptic inhibition: regulation of exocytotic fusion downstream of $\mathrm{Ca}^{2+}$ entry. Science 292:293-297.

Chow RH, von Ruden L, Neher E (1992) Delay in vesicle fusion revealed by electrochemical monitoring of single secretory events in adrenal chromaffin cells. Nature 356:60-63.

Cousin MA, Robinson PJ (2000) $\mathrm{Ca}^{2+}$ influx inhibits dynamin and arrests synaptic vesicle endocytosis at the active zone. J Neurosci 20:949957.

Cremona O, De Camilli P (1997) Synaptic vesicle endocytosis. Curr Opin Neurobiol 7:323-330.

Engisch KL, Nowycky MC (1998) Compensatory and excess retrieval: two types of endocytosis following single step depolarizations in bovine adrenal chromaffin cells. J Physiol (Lond) 506:591-608.

Gillis KD (1995) Techniques for membrane capacitance measurements In: Single-channel recordings (Sakmann B, Neher E, eds), pp155-198. New York: Plenum.

Hanson PI, Roth R, Morisaki H, Jahn R, Heuser JE (1997) Structure and conformational changes in NSF and its membrane receptor complexes visualized by quick-freeze/deep-etch electron microscopy. Cell 90:523-535.

Hay JC, Scheller RH (1997) SNAREs and NSF in targeted membrane fusion. Curr Opin Cell Biol 9:505-512.

Heidelberger R (1998) Adenosine triphosphate and the late steps in calcium-dependent exocytosis at a ribbon synapse. J Gen Physiol 111:225-241.

Heidelberger R (2001) Electrophysiological approaches to the study of neuronal exocytosis and synaptic vesicle dynamics. Rev Physiol, Biochem, Pharmacol 143:1-80.

Heidelberger R, Matthews G (1992) Calcium influx and calcium current in single synaptic terminals of goldfish retinal bipolar neurons. J Physiol (Lond) 447:235-256.

Heidelberger R, Heinemann C, Neher E, Matthews G (1994) Calcium dependence of the rate of exocytosis in a synaptic terminal. Nature 371:513-515.

Heinemann C, Chow RH, Neher E, Zucker RS (1994) Kinetics of the secretory response in bovine chromaffin cells following flash photolysis of caged $\mathrm{Ca}^{2+}$. Biophys J 67:2546-2557.

Henkel AW, Almers W (1996) Fast steps in exocytosis and endocytosis studied by capacitance measurements in endocrine cells. Curr Opin Neurobiol 6:350-357.

Hess SD, Doroshenko PA, Augustine GJ (1993) A functional role for GTP-binding proteins in synaptic vesicle cycling. Science 259:1169-1172.

Hsu SF, Jackson MB (1996) Rapid exocytosis and endocytosis in nerve terminals of the rat posterior pituitary. J Physiol (Lond) 494:539-553.

Kaneko A, Tachibana M (1985) A voltage-clamp analysis of membrane currents in solitary bipolar cells dissociated from Carassius auratus. J Physiol (Lond) 358:131-152.

Kavalali ET, Klingauf J, Tsien RW (1999) Properties of fast endocytosis at hippocampal synapses. Philos Trans R Soc Lond B Biol Sci 354:337-346.

Kawasaki F, Mattiuz AM, Ordway RW (1998) Synaptic physiology and ultrastructure in comatose mutants define an in vivo role for NSF in neurotransmitter release. J Neurosci 18:10241-10249.

Klingauf J, Kavalali ET, Tsien RW (1998) Kinetics and regulation of fast endocytosis at hippocampal synapses. Nature 394:581-585.

Koenig JH, Ikeda K (1996) Synaptic vesicles have two distinct recycling pathways. J Cell Biol 135:797-808.

Lamaze C, Fujimoto LM, Yin HL, Schmid SL (1997) The actin cytoskeleton is required for receptor-mediated endocytosis in mammalian cells. J Biol Chem 272:20332-203325.

Lindau M, Neher E (1988) Patch-clamp techniques for time-resolved capacitance measurements in single cells. Pflügers Arch 411:137-146. 
Messler P, Harz H, Uhl R (1996) Instrumentation for multiwavelengths excitation imaging. J Neurosci Methods 69:137-147.

Miller TM, Heuser JE (1984) Endocytosis of synaptic vesicle membrane at the frog neuromuscular junction. J Cell Biol 98:685-698.

Neves G, Lagnado L (1999) The kinetics of exocytosis and endocytosis in the synaptic terminal of goldfish retinal bipolar cells. J Physiol (Lond) 515:181-202.

Nucifora PG, Fox AP (1999) Tyrosine phosphorylation regulates rapid endocytosis in adrenal chromaffin cells. J Neurosci 19:9739-9746.

Pusch M, Neher E (1988) Rates of diffusional exchange between small cells and a measuring patch pipette. Pflügers Arch 411:204-211.

Qualmann B, Kessels MM, Kelly RB (2000) Molecular links between endocytosis and the actin cytoskeleton. J Cell Biol 150:F111-F116.

Ramaswami M, Krishnan KS, Kelly RB (1994) Intermediates in synaptic vesicle recycling revealed by optical imaging of Drosophila neuromuscular junctions. Neuron 13:363-375.

Rouze NC, Schwartz EA (1998) Continuous and transient vesicle cycling at a ribbon synapse. J Neurosci 18:8614-8624.

Sankaranarayanan S, Ryan TA (2001) Calcium accelerates endocytosis of vSNAREs at hippocampal synapses. Nat Neurosci 4:129-136.

Schaeffer SF, Raviola E (1978) Membrane recycling in the cone cell endings of the turtle retina. J Cell Biol 79:802-825.

Schmid SL, Carter LL (1990) ATP is required for receptor-mediated endocytosis in intact cells. J Cell Biol 111:2307-2318.

Schmid SL, Smythe E (1991) Stage-specific assays for coated pit formation and coated vesicle budding in vitro. J Cell Biol 114:869-880.

Schmid SL, McNiven MA, De Camilli P (1998) Dynamin and its partners: a progress report. Curr Opin Cell Biol 10:504-512.
Scott RH, Pearson HA, Dolphin AC (1991) Aspects of vertebrate neuronal voltage-activated calcium currents and their regulation. Prog Neurobiol 36:485-520.

Smith C, Neher E (1997) Multiple forms of endocytosis in bovine adrenal chromaffin cells. J Cell Biol 139:885-894.

Smythe E, Pypaert M, Lucocq J, Warren G (1989) Formation of coated vesicles from coated pits in broken A431 cells. J Cell Biol 108:843-853.

Tachibana M, Okada T, Arimura T, Kobayashi K, Piccolino M (1993) Dihydropyridine-sensitive calcium current mediates neurotransmitter release from bipolar cells of the goldfish retina. J Neurosci 13:2898-2909.

Thomas P, Lee AK, Wong JG, Almers W (1994) A triggered mechanism retrieves membrane in seconds after $\mathrm{Ca}^{2+}$-stimulated exocytosis in single pituitary cells. J Cell Biol 124:667-675.

von Gersdorff H, Matthews G (1994a) Dynamics of synaptic vesicle fusion and membrane retrieval in synaptic terminals. Nature 367:735-739.

von Gersdorff H, Matthews G (1994b) Inhibition of endocytosis by elevated internal calcium in a synaptic terminal. Nature 370:652-655.

von Gersdorff H, Sakaba T, Berglund K, Tachibana M (1998) Submillisecond kinetics of glutamate release from a sensory synapse. Neuron 21:1177-1188.

Wu LG, Betz WJ (1996) Nerve activity but not intracellular calcium determines the time course of endocytosis at the frog neuromuscular junction. Neuron 17:769-779.

Zenisek D, Matthews G (2000) The role of mitochondria in presynaptic calcium handling at a ribbon synapse. Neuron 25:229-237. 